
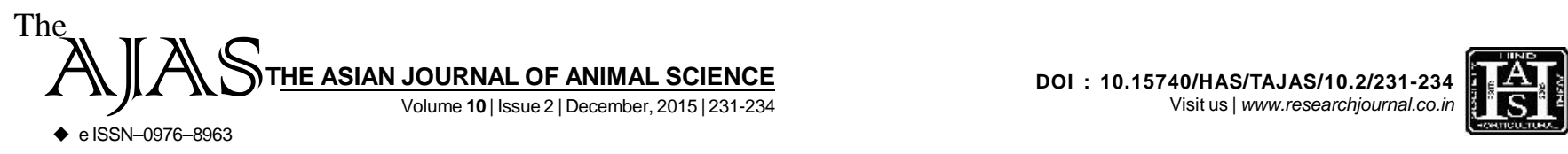

ARTICLE.........

\title{
Study of web pattern in spiders
}

VINOD KUMARI, KAILASH SAINI AND N.P. SINGH

Author for Corresponding -

VINOD KUMARI

Department of Zoology,

University of Rajasthan, JAIPUR

(RAJASTHAN) INDIA

See end of the article for

Coopted authors'

\section{KEY WORDS...... Rajasthan, Spiders}

HOW TO CITE THIS ARTICLE - Kumari, Vinod, Saini, Kailash and Singh, N.P. (2015). Study of web pattern in spiders. Asian J. Animal Sci., 10(2): 231-234.

ARTICLE CHRONICLE - Received : 19.10.2015; Accepted : 30.11.2015
Spiders secrete silk for many purposes- to protect their young ones, catch food, make houses and move around. Spider silk is an elastic and sometimes adhesive material. Silk is secreted as a fluid, which hardens as it oozes out of the silk spinning organs or spinnerets that are mobile finger like projections. Webs (a characteristic feature of spiders) built out of silk are used to catch insects, making web building spiders efficient predators and even biological control agents (Riechert, 1999 and Symondson et al., 2002). In a typical field survey the majority of spiders collected cannot be identified to species level because of being juveniles (Brennan et al., 2004). Web building spider communities can be assessed and identified on the basis of characteristics of their web architecture (Gollan et al., 2009). The evolution of the web is itself has been studied extensively (Benjamin and Zschokke, 2004 and Gan et al., 2015). A number of efforts have been made to trace the history and relationship of species of relationship of species by means of web-resemblances under the assumption that a more "Primitive", simple and irregular web was the forerunner of the more elaborate patterns.

Web building is very sensitive to disturbance, especially during the early stages of web building (Zschokke, 1996), because of this, we selected particularly non- disturbing sites in experimental region to study and observe the webs. Web study was undertaken in Patan (Sikar, Rajasthan) and caves and rocky area around the Katali River in Khandella (Sikar, Rajasthan). Since spider web-threads are very thin $(0.5$ to $5 \mu \mathrm{m}$ ), so taking the pictures of webs requires the clear visibility of threads. To increase the thread visibility we used a highly resolving camera (Nikon). The record of every photograph was maintained in laboratory notebook.

The main requirements to capture highly clear photographs of spider-webs are bright light from the sides and a very dark background, in this order; we applied a black sheet of rigid paper as dark background putting just behind the web threads. During web observations, a few numbers of egg sacs and spiderlings were also found entangled in webs of some spider species. These egg sacs and spiderlings were also collected in plastic jars separately and were subjected to be reared in laboratory studying the biology and feeding efficacy of these species. The webs observed from study area were examined, identified and discussed on the basis of matching the architecture and photographs of webs with the description of webs given by Witt et al. (1968) and Sebestian and Peter (2009). 